Thorax, 1980, 35, 929-931

\title{
Sequential brush biopsy and conventional biopsy: direct comparison of diagnostic sensitivity in lung malignancy
}

\author{
J R W LYALL, G D SUMMERS, I M O'BRIEN, N T BATEMAN, C P PIKE, \\ AND M V BRAIMBRIDGE \\ From the Departments of Medicine, Cardiothoracic Surgery, and Cytopathology, \\ St Thomas' Hospital, London
}

ABSTRACT One hundred and sixteen patients with suspected lung malignancy who were referred for bronchoscopy were examined using both the flexible fibreoptic bronchoscope and the rigid bronchoscope. Both instruments were used sequentially under the same general anaesthetic. Brush biopsies were obtained through the fibreoptic bronchoscope and conventional biopsies, for histological examination, through the rigid bronchoscope. Both specimens were taken from the same area. Eighty-two per cent of those in whom there was a final clinical diagnosis of malignancy were found to have abnormal cytology via the fibreoptic bronchoscope, while abnormal histology was found in $50 \%$ by means of the rigid bronchoscope. For those in whom malignancy was confirmed, $16.9 \%$ showed disagreement between the two methods in cell typing. Brush biopsy through the flexible fibreoptic bronchoscope under general anaesthesia is confirmed as a sensitive method for diagnosing lung malignancy.

For many years, bronchial biopsy through the rigid bronchoscope has been a valuable technique in the diagnosis of lung malignancy. The material obtained allows for conventional histological examination. The sensitivity of this technique is established, ${ }^{1-3}$ and may be regarded as a standard against which to assess new methods.

Brush biopsy, which provides material for cytological examination, has been performed through the rigid bronchoscope or with a flexible catheter. ${ }^{4}$ Since the introduction of the flexible fibreoptic bronchoscope ${ }^{56}$ however, brush biopsy has been advocated as a highly sensitive method of diagnosis. ${ }^{7}$ There is no published study comparing the diagnostic sensitivity of brush biopsy through the fibreoptic bronchoscope with conventional biopsy through the rigid bronchoscope carried out sequentially at the same examination by an operator experienced in both techniques. We have used both methods in a group of patients with suspected lung malignancy. The examinations were carried out sequentially under the same general anaesthetic and

Address for reprint requests: Dr GD Summers, Department of Medicine, St Thomas' Hospital, London SE1 7EH. the findings compared with the final clinica diagnosis.

\section{Methods}

The study was carried out on patients with suspected malignancy referred for routine bronchoscopy in the outpatient theatre at St Thomas' Hospital. All examinations were carried out under general anaesthesia, using a technique previously described ${ }^{9}$ which allows introduction of the fibreoptic bronchoscope through a diaphragm in the end of a cuffed endotracheal tube, whilst permitting ventilation through a side connection. An Olympus BF 5B2 fibreoptic bronchoscope was introduced and each segmental orifice visualised. Brush biopsy of the abnormal area was obtained for cytological examination. After brushing, the bronchoscope and brush were withdrawn as one, without retraction of the brush into the biopsy channel, and the brush was immediately rubbed on a microscope slide using a circular motion. The slide was immersed in $90 \%$ ethanol for fixing and transport to the laboratory. Forcep biopsy specimens were not taken with the fibreoptic bronchoscope. 
After removal of the endotracheal tube, examination by means of a rigid Negus bronchoscope was carried out on those patients who had not presented an entirely normal appearance through the fibreoptic bronchoscope. Appropriate biopsies were taken with Brock biopsy forceps for paraffin section histological examination, from the same area which had been previously brushed with the fibreoptic bronchoscope cytology brush.

The diagnosis made using each technique was compared with the final clinical diagnosis.

\section{Results}

One hundred and sixteen patients were examined using both techniques. The age and sex distribution are shown in table 1 . Of the 116 patients, 99 had a diagnosis of malignancy confirmed at follow-up. Of those patients with a final diagnosis of malignancy, $50(50 \%)$ were detected by conventional

Table 1 Age and sex distribution of patients studied

\begin{tabular}{lll}
\hline & Patients & \\
\cline { 2 - 3 } & Male & Female \\
\hline Number & 90 & 26 \\
Age range (yr) & $18-76$ & $48-79$ \\
Mean age (yr) & 61 & 62 \\
\hline
\end{tabular}

Table 2 Results of histology and cytology

\begin{tabular}{llll}
\hline & Malignant & Benign & Total \\
\hline Final diagnosis & 99 & 17 & 116 \\
Histological diagnosis & 50 & 66 & 116 \\
Cytological diagnosis & 81 & 35 & 116 \\
\hline
\end{tabular}

Table 3 Bronchoscopic findings for the 99 cases of confirmed malignancy

\begin{tabular}{lll}
\hline & Number & $(\%$ total $)$ \\
\hline Both methods diagnostic & 46 & 47 \\
Cytology only diagnostic & 35 & 35 \\
Histology only diagnostic & 4 & 4 \\
Both methods negative & 14 & 14 \\
Total & 99 & \\
\hline
\end{tabular}

Table 4 Comparison of cell type obtained by cytology and histology

\begin{tabular}{|c|c|c|c|c|c|c|}
\hline & & \multicolumn{5}{|l|}{ Cytology } \\
\hline & & Negative & Squamous & Oat & Anaplastic & Other \\
\hline \multirow{5}{*}{ 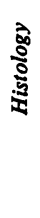 } & Negative & 31 & 18 & 4 & 8 & 5 \\
\hline & Squamous & 1 & 27 & & 1 & \\
\hline & Oat & & . & 4 & 7 & \\
\hline & $\begin{array}{l}\text { Anaplastic } \\
\text { Other }\end{array}$ & 3 & 1 & & 3 & 3 \\
\hline & \multicolumn{2}{|c|}{$\begin{array}{c}\text { Cell type } \\
\text { agrees } \\
37\end{array}$} & oth +46 & \multicolumn{2}{|c|}{$\begin{array}{c}\text { Cell type } \\
\text { disagrees } \\
9\end{array}$} & \\
\hline
\end{tabular}

histological examination of biopsies obtained through the rigid bronchoscope, and $81(81 \cdot 8 \%)^{\frac{5}{7}}$ were detected by examination of the cytological $\mathbb{Q}$ preparations obtained by brush biopsy through the fibreoptic bronchoscope (table 2). Table 3 shows $-\overrightarrow{0}$ the combined and individual bronchoscopic findings in the 99 cases of confirmed malignancy. Table $4 \vec{\omega}$ shows the cell types obtained by each method. In the 46 in whom both methods yielded a positive diagnosis, there was agreement in 37. In nine w్ diagnosis of malignancy was made by both techniques, but the cell type disagreed.

\section{Discussion}

The present results confirm previous reports suggesting a greater sensitivity of brush biopsy ovek conventional biopsy. ${ }^{10}$ Previous studies have onl ${ }_{3}^{\mathbb{8}}$ compared the two techniques retrospectively different groups of patients being examined by different operators. In the present study the sam\& operator, familiar with both bronchoscopic methods, carried out the examinations sequentially on the same patient.

Although the fibreoptic bronchoscope extend the range of vision and biopsy, ${ }^{6}{ }^{11}$ we included iro this study only those patients in whom a biops could be taken through the rigid bronchoscope. We have, therefore, carried out a direct comparison of the sensitivity of the two biopsy techniques.

Cytological preparations can deteriorate rapidls and meticulous attention to detail when taking the specimen is most important. Our technique under general anaesthesia permits rapid withdrawa此 of bronchoscope and brush together, with the bruslo still protruding beyond the end of the bronchoscope Harvested cells were smeared on to a glass slidę with a circular motion and immediately plunge $\Phi$ into fixative. We found that as little as 15 secondo delay between harvest and fixation could produce $\vec{a}$ noticeable deterioration in cell quality on subo sequent cytological examination.

Oswald et $a l^{2}$ reported a sensitivity for rigi bronchoscopy of $50 \%$. Webb and Clarke, ${ }^{12}$ in कु retrospective survey, reported positive biopsy rate岕 of $51 \%$ for rigid bronchoscopy and $72 \%$ for fibreo optic bronchoscopy carried out under loca्d anaesthesia, taking biopsy but not cytolog布 specimens. When allowance was made for tumours? outside the range of the rigid bronchoscope -0 that is, comparable to the present study-theip positive rate for fibreoptic bronchoscopy was $47 \%$

The positive biopsy rate of $50 \%$ obtained in th present study using the rigid bronchoscope is ip keeping with these previous reports. The muck higher positive fibreoptic cytology rate of $82^{\circ}$ 角 
cannot be easily explained, as biopsy and cytology specimens were deliberately taken from the same abnormal area. It may be that cell harvest by brushing collects a sample from a wider area than forcep biopsy.

Comparison of cell types obtained by conventional histology and brush biopsy shows only moderate agreement, $20 \%$ yielding a different cell type. We have obtained confirmatory histology from operation or postmortem examination in too few of our patients to allow determination of the absolute accuracy for each method. This is clearly of importance, particularly in those patients for whom chemotherapy may be considered. We feel that the high sensitivity of brush biopsy using the fibreoptic bronchoscope under general anaesthesia makes this the diagnostic technique of choice for patients with suspected lung malignancy.

\section{References}

1 Somner AR, Hillis BR, Douglas AC, Marks BL, Grant IWB. Value of bronchoscopy in clinical practice. Br Med J 1958; 1:1079-84.

2 Oswald NC, Hinson KFW, Canti G, Miller AB. The diagnosis of primary lung cancer with special reference to sputum cytology. Thorax 1971 ; 26:62331.
3 Payne CR, Stovin PGI, Barker V, McVittie S, Stark JE. Diagnostic accuracy of cytology and biopsy in primary bronchial carcinoma. Thorax 1979; 34:294-9.

4 Zavala DC, Rossi NP, Bedell GN. Bronchial brush biopsy. Ann Thorac Surg 1972; 13:519-26.

5 Ikeda S, Yanai N, Iskihawa S. Flexible bronchofiberoscope. Keio J Med 1968; 17:1-16.

6 Ikeda S. Flexible bronchofiberscope. Ann Otol Rhinol Laryngol 1970; 79:916-23.

7 Richardson RH, Zavala DC, Mukerjee PK, Bedell GN. The use of fibreoptic bronchoscopy and brush biopsy in the diagnosis of suspected pulmonary malignancy. Am Rev Respir Dis 1974; 109:63-6.

8 Solomon DA, Solliday NH, Gracey DR. Cytology in fibreoptic bronchoscopy. Chest 1974; 65:616-9.

9 Lett Z, Ong GB. Anaesthesia for flexible fibreoptic bronchoscopy. Anaesthesia 1974; $29: 623-5$.

10 Webb J, Clarke SW. Comparison between the positive biopsy rates in lung cancer achieved with the rigid bronchoscope and with the fibreoptic bronchoscope. Thorax 1978; 33:531-2.

11 Kovnat DM, Rath GS, Anderson WM, Sinder GL. Maximal extent of visualization of bronchial tree by flexible fibreoptic bronchoscopy. Am Rev Respir Dis 1974; 110:88-90.

12 Webb J, Clarke SW. A comparison of biopsy results using rigid and fibreoptic bronchoscopes. $\mathrm{Br} \mathrm{J}$ Dis Chest 1980; 74:81-3. 